\title{
Mnemonic Instruction: A Way to Boost Vocabulary Learning and Recall
}

\author{
Mohammad Amiryousefi \\ ACECR, Isfahan University of Technology, Isfahan, Iran \\ Email: M.Amiryousefi@Yahoo.com \\ Saeed Ketabi \\ Department of English, Faculty of Foreign Languages, University of Isfahan, Isfahan, Iran \\ Email: Ketabi@fgn.ui.ac.ir
}

\begin{abstract}
Traditionally, vocabulary was neglected in language teaching programs and curriculums for the sake of grammar and other parts of language. Nowadays, however, researchers have realized that vocabulary is an important part of language learning and teaching and worthy of attention and research. A proliferation of studies done on vocabulary can be taken as a proof to it. Students are, however, reported to frustrate when they face with new words, since they have difficulty retaining them. This paper provides information on how mnemonics devices can be used to solve this problem and to improve vocabulary learning, boost memory and enhance creativity.
\end{abstract}

Index Terms - mnemonic devices, VLS, linguistic mnemonics, spatial mnemonics, visual mnemonics, the verbal method, physical responses methods

\section{INTRODUCTION}

In the literature of English language teaching and learning a recurring theme has been the neglect of vocabulary. It was often given little priority in language programs and was often left to look after itself and received only incidental attention in textbooks and language programs (Hedge, 2008; Richards and Renandya, 2002).French (1983) believes that vocabulary has been neglected in the past decades because 1) those who were involved in the teacher-preparation programs during the past few decades felt that grammar should be emphasized more than vocabulary, 2)specialists in methodology believed that students would make mistakes in sentence construction if too many words were learned before the basic grammar had been mastered, and 3)those who gave advice to teachers said that word meanings can be learned only through experience and can not be taught in the classroom. More recently, however, a number of researchers have become interested in vocabulary instruction. They have wakened to the realization that vocabulary is an important area worthy of effort and investigation. It has, consequently, gained popularity in the general field of English language teaching and learning (Coady and Huckin, 1997; Richards and Renandya, 2002; Hedge, 2008). There is now general agreement among vocabulary specialists that it is at the heart of communicative competence (Coady and Huckin, 1997).

Vocabulary learning strategy (VLS) is an approach which facilitates vocabulary learning and has attracted considerable attention. It is a movement away from teaching- oriented approach toward one that is interested in seeing how actions of learners might affect their acquisition of vocabulary (Schmitt, 2002).Strategies can help learners both in discovering the meaning of a word, and consolidating it and are specially needed when they are encouraged to learn independently(Celce-Murcia, 2001). One of the problems that students mostly face is that they easily forget the newly learned words. To solve this problem, researchers have attempted to examine different VLSs. Mnemonic devices or strategies have proved to make substantial contribution in this regard (Farjami, 2007). They, however, have not been researched in any depth and English teachers are not usually aware of their effectiveness and do not know how to use them. This study, therefore, intends to discuss mnemonic devices in depth.

\section{MNEMONICS: DEFINITION}

The word mnemonic is derived from the Greek word Mnemosyne, referring to the ancient Greek goddess of memory. The use of mnemonic dates back to 500B.C (Yates, 1966). The first used mnemonic device was an earlier form of the modern day method of loci and since then, numerous other devices have been developed (Higbee, 1987). Memory has a key effect on eventual vocabulary and grammar achievement. There are two basic types of memory: short-term memory and long-term memory. Short term memory keeps the information which is being processed (a new word which is encountered for the first time).It is fast but it can hold information for a very short time due to its small storage capacity. Long term memory, on the other hand, has an unlimited storage capacity but is relatively slow. The aim of vocabulary learning and teaching is to transfer the lexical information from the short term memory to the long term memory 
(Schmitt, 2000, 129-131). Aitchison (2002), however, believes that our mind is like the London Underground System. By this he means that information stored in the brain is linked in different ways. Accordingly, the general picture of the mental lexicon is one in which there a variety of links between words, some strong, some weak. The main way, to transfer the vocabulary items from short term to long term memory and create a strong connection there is by finding some elements in the mental lexicon to attach the new lexical item to (Schmitt, 2000). Mnemonic is a memory enhancing instructional strategy that involves teaching students to link new information taught to information they already know.

According to Solso (1995), mnemonics are techniques or devices, either verbal or visual in nature, that serve to improve the storage of new information, and the recall of information contained in memory. Mnemonics have been proven to be extremely effective in helping people remember things (Mastropieri \& Scruggs, 1989; Bulgren, Schumaker $\&$ Deshler, 1994). If material is presented in a way which fits in or relates meaningfully to what is already known, then it will be retained for relatively long periods of time and thus retrieval through verbal or visual clues becomes quite easy. In other words, by using mnemonic strategies, teachers can relate new information to information students already have stored in their long-term memory. For vocabulary learning, they are used to relate the word to some previously learnt information, using some form of imagery or grouping (Mastropieri and Scruggs, 1991). Thompson (1987) similarly acknowledging the usefulness of mnemonic devices by stating that they can help learners learn faster and recall better by integration of new material into existing cognitive units and by providing retrieval cues. Mnemonic devices are proved to be effective in all ages. They are, however, more useful for low level students because they are involved mostly in activities requiring them to remember and recall information (Levin, 1993).

\section{MNEMONICS: CLASSIFICATION}

Mnemonic devices have been differently classified by different scholars. Thompson (1987), for example, arranges mnemonic strategies into five classes; linguistics, spatial, visual, physical response and verbal methods. Oxford (1990), on the other hand, identifies four major strategies namely, creating mental linkage, applying images and sounds, reviewing well, and employing action. While Baddeley (1999) believes that mnemonic devices are classified into visual imagery strategies and verbal strategies. This study, however, adopts the one presented by Thompson which sounds to be more comprehensive.

\section{A. Linguistic Mnemonics}

1. Peg word method

Through peg word method unrelated items can be remembered easily by relating them to easily memorizable items which act as pegs or hooks. Peg word method has two stages. At first students are asked to remember 10 number-rhyme pairs like one is bun or john, two is shoe, three is tree ( in my classes I usually continue it in this way: four is door, five is hive, six is cheeks, seven is heaven, eight is gate, nine is pine, ten is hen). In the second stage the students are asked to visualize the word and try to link it to rhyming words. The words are, therefore, learned in a composite picture of the given word and the peg (Roediger, 1980; Groeger, 1997; Mirhassani and Eghtesadei, 2007). For example if the first word to be learned is "exploration", its peg can be "John" and after its meaning is defined to the students, they can form a metal picture in which "John is doing oil explorations", if the second one is "feature", its peg according to the rhyme pairs can be "shoe" and the students can form a mental picture in which some people are talking about the features of a kind of shoe.

2. The key word method

Key word method according to Hulstijn (1997) requires three stages. At first An L1 or L2 word that has acoustic similarity to the target word is given to the learner to act as the key word. In the second stage the learner is asked to make an association between the target word and the keyword. Finally he is asked to make a mental image of the combination of the keyword and the target word. For example the word "shear' means to cut the wool off a sheep and it is acoustically similar to the Persian word شير(shir), lion in English. It can be given to the learner as the keyword and then he is asked to associate them in a mental picture. The learner may associate them in this way: A Shir (lion) is shearing a sheep.

\section{B. Spatial Mnemonics}

\section{The loci method}

Loci method is actually the oldest mnemonic device. Using this method entails imagining a very familiar place like a room or a house and then associating each new word to a part of it to be remembered (Eysenck, 1994; Mirhassani and Eghtesadei, 2007). In other words, the students take an imaginary walk along their familiar places, and retrieve the items they have put there. As people's experiences are different, students may come up with different pictures (Thomson, 1987). For example if the new words to be learned are era, artificial, mission, sample, mass, density, disturb, distant, the familiar location can be the moon and the mental picture formed may be ( as an example from my own class): "It is the robot era. There are some robots with artificial hands and legs. They are on a mission on the moon. They are collecting a mass of sample rocks to examine their features and density. No one can disturb them because they are in a distant area". They all must be seen as a mental and imagined picture by the students. 


\section{Spatial grouping}

The idea behind this method is that instead of writing words in a column, students can be asked to form patterns like a triangle with them. Writing words in the form of patterns help them recall the words better (Holden, 1999). As they remember the pattern, they can remember the parts which are signed by the words.

3. The finger method

Through this method students can be asked to associate each word with a finger. This method is especially useful with children to learn numbers, days of the week and month of the year (Holden, 1999).

\section{Visual Mnemonics}

\section{Pictures}

New words are usually paired with their definitions or equivalents. They can be, however, better, learned if they are paired with pictures (Thompson, 1987). Gians and Redman (1986) believe that objects and pictures can facilitate recall. Wright (1989) also believes that meaning can not be derived only from verbal language. Pictures and objects not only can be used to give meaning and information but they also can be used to the motivation and interest of the students. Using this method, a picture can be used to make the meaning of the word clear. It can sometimes be accompanied by its definition. This method can, however, be used with concrete words and usually with elementary or pre-intermediate students.

2. Visualization or imagery

Instead of using real pictures, this method allows a word to be visualized. The learner imagines a picture or a scene which is associated with the target word. Abstract words can be learned through this method by relating them to a visual picture (Holden, 1999; Thompson, 1987; Mirhassani and Eghtesadei, 2007). Visualization can be an aid in vocabulary learning (O'Malley and Chamot, 1990). If the new word is "exploration", the learner may come up with this mental picture "A scientist is using special drills for oil exploration" by relating it to the picture of a scientist. Again the students may come up with different pictures because people's experiences are different. Its difference with the method of loci is that in visualization for each word a picture or a scene is imagined while in the method of loci all of them are related to a familiar place and seen as an imaginary walk through that place.

\section{The Verbal Method}

\section{Grouping or semantic organization}

As organized materials are easier to store in and retrieve from long-term memory, to organize the words in some fashion will enhance their recall (Anderson, 2000; Thomson, 1987). If the target words to be remembered are, for example, dog, cat, chair, sofa, table, milk, eggs and butter they can be organized and remembered under three categories: animals ( for dog and cat ), furniture ( for chair, sofa and table) and food ( for milk, egg and butter). In this way learners have the advantage of better recall than when they all are learned in a list, because if they can remember one word, they will be able to remember the rest (Mirhassani and Eghtesadei,2007).

2. Story-telling or the narrative chain

In this method the learner links the words together by a story. At first he should associate the target words with a topic or some topics, then he should connect them by making up a story containing the words (Thompson, 1987; Holden, 1999; Mirhassani and Eghtesadei, 2007). This method is especially useful for high level students.

\section{E. Physical Responses Methods}

\section{Physical response method}

According to this method the learner should move his body or parts of his body in a certain way that illustrates the meaning of the word. If the target word is tiptoe, for example, the student can get up on his tiptoe and move across the room. It can be imaginary too. It means that he can imagine the action of moving on his tiptoe (Thompson, 1987; Holden, 1999). Thompson (1987) especially believes that if the information of a word or a sentence is enacted it can yield better understanding and recall.

2. Physical sensation method

This strategy is devised by Oxford and Scarcella (1994). Through this method the learner associates the new word to a physical sensation. For example he can feel cold when he learns the word frigid.

\section{COMMENTS ON THE USE OF MNEMONIC DEVICES}

Mnemonic devices can be very effective and can make the students motivated and the classroom more interesting (Georger, 1997). There are, however, some points that interested teachers should consider: 1) learners themselves should be encouraged to find their mnemonic devices. If they can not the teacher can offer one; 2) it is not often possible to use certain mnemonic devices with certain words. It is, for example, difficult to find a key word for certain words. The students also vary in their abilities. For some imagery techniques can be more effective while for others verbal strategies, for example. Worthen and Hunt (2008), accordingly, suggest that a specific combination of processes is necessary for the effectiveness of mnemonic instruction and use. The teachers should, therefore, use several techniques at the same time; 3) the use of certain devices entails a certain level of proficiency. Students with different 
levels of proficiency may need different techniques. High- level students may, for example, benefit more from verbal than from visual devices; 4) students should be encouraged to evaluate their own techniques and finally 5) when certain strategies are agreed up on, the teacher should instruct the strategy and its importance and effectiveness (Hulstijn, 1997; Thompson, 1987; Holden, 1999; Mirhassani and Eghtesadei, 2007).

\section{STUdies Done on THE EFFeCTIVENESS OF MNEMONIC DEVICES}

A lot of studies have focused on the recognition and instruction of language learning strategies in general and vocabulary in particular. There are, however, a few studies done on mnemonic devices. Those focused on mnemonic devices have consistently indicated that the use of mnemonic devices substantially enhances higher levels of retention in immediate and delayed recall of second language vocabulary words in comparison with other learning strategies. For example, Raugh and Atkinson (1975) compared the keyword method with various control procedures for learning a Spanish vocabulary. In all cases, the keyword method proved to be highly effective, yielding in one experiment a final test score of $88 \%$ correct for the keyword group compared to $28 \%$ for the control group. Moreover, Pressly et al (1981) studied on children 3 to 6 years of age learning simple Spanish vocabulary items through keyword method. The results showed that children who used the keyword method remembered more vocabulary than children who were not instructed in keyword method usage. Carlson, Kincaid, Lance, and Hodgson (1976), however, found significantly better recall when a group trained on the method of loci was compared to a control group. Another study by Roediger (1980) looked at the method of loci along with three other well-known mnemonic methods. Results of the study revealed that all four mnemonic groups recalled the 20 -word list better than the control group. However, the method of loci and the peg word system were found to be better methods to use when the order of words remembered was important. Erten and Tekin (2008) investigated the effects of semantic organization on vocabulary recall on a group of 60 fourth graders. They were taught 80 carefully selected words either in semantically related sets or semantically unrelated set. The statistical analysis, however, revealed that learning words in semantically unrelated sets yields better results than learning vocabulary in semantically related sets. The study indicated that, contrary to frequent practice in many course books, presenting new vocabulary that belongs to the same semantic set together may cause interference due to crossassociation and may even hinder vocabulary learning. Atay and Ozbulgan (2007) investigated the effects of memory strategy instruction along with learning through context on the ESP vocabulary recall of Turkish EFL learners. The study showed that memory strategies or mnemonic strategies can improve vocabulary learning. The result of the study also illustrated that first; strategy instruction should be integrated into contextual vocabulary learning. After discovering the meaning of a word through different contexts, students should be guided to recall it via different memory strategies. Secondly, rather than providing the learners with one or two strategies, the instruction should focus on the whole array of strategies, and students should be asked to choose the most effective one(s) for themselves. To do so teachers should be instructed about the use and instruction of different strategies.

\section{CONCLUSION}

One of the most challenging parts of every language learning is the acquisition of vocabulary items. Students, however, complain that they can not remember the words they have learned. To solve this problem, teachers can attempt to include mnemonic devices into their classes. Mnemonic devices are useful ways of enhancing vocabulary learning and recall. Such memory techniques should not replace other approaches to vocabulary learning, but should complement them. Research on the effectiveness of mnemonic strategies has consistently proved their usefulness, it, however, recommends language teachers not to present words in isolation, but rather use these devices in contextual vocabulary learning. The choice of strategies, however, depends on the students' proficiency and learning style (Coady and Huckin, 1997; Thompson, 1987; Holden, 1999; Mirhassani and Eghtesadei, 2007).

\section{REFERENCES}

[1] Aitchison, J. (2002). Words in the Mind: An Introduction to the Mental Lexicon (3rd Ed.). Blackwell Publishers: Great Britain.

[2] Anderson, J. R. (2000).Cognitive psychology and Its Implication ( $5^{\text {th }}$ Ed.).New York: Worth Publishers.

[3] Atay, D. \& Ozbulgan, C. (2007). Memory strategy instruction, contextual learning and ESP vocabulary recall. English for Specific Purposes, 26, 39-51.

[4] Baddeley, A.D. (1999). Essentials of Human Memory. East Sussex: Psychology Press Ltd.

[5] Bulgren, J. A., Schumaker, J. B., \& Deshler, D. D. (1994). The effects of a recall enhancement routine on the test performance of secondary students with and without learning disabilities. Learning Disabilities Research \& Practice, 9, 2-11.

[6] Carlson, R.F., Kincaid, J.P., Lance, S. \& Hodgson, T.( 1976). Spontaneous use of mnemonics grade point average. Journal of Psychology, 92(1), 117-122.

[7] Carney R. N. \& Levin J. R. (1988). Do Mnemonic Fade as Time Goes By? Here's Looking Anew! Contemporary Educational Psychology, 23, 276-297.

[8] Carney, R. N., \& Levin, J. R. (2000). Mnemonic instruction with a focus on transfer. Journal of Educational Psychology, 92(4), 783-790.

[9] Celce-Murcia, M. (2001). Teaching English as a Second or Foreign Language. USA: Heinle and Heinle.

[10] Coady, J. \& Huckin, T. (1997). Second language Vocabulary Acquisition. USA: Cambridge University Press. 
[11] Erten, I.H. \& Tekin, M. (2008). Effects on vocabulary acquisition of presenting new words in semantic sets versus semantically unrelated sets. System 36, 407-422.

[12] Eysenck, M.W. (1994). Principles of Cognitive Psychology. Hillsdale: Erlbaum Association.

[13] Farjami, H. (2007).Picture production and picture perception: comparing two modes of practicing concrete vocabulary. IJAL, 10(1).

[14] French, A.V. (1983). Techniques in Teaching Vocabulary. Oxford: Oxford University Press.

[15] Gains, R., \& Redman, S. (1986). Working with Words: A Guide to Teaching and Learning Vocabulary. Cambridge: Cambridge University Press.

[16] Groeger, A. J. (1997). Memory and Remembering: Everyday Memory in Context. New York: Longman.

[17] Hedge, T. (2008). Teaching and Learning in the Language Classroom. Oxford: Oxford University Press.

[18] Higbee, K. L. (1987). Process mnemonics: Principles, prospects, and problems. In M. A. McDaniel \& M. Pressley (Eds.), Imagery and Related Mnemonic Processes: Theories, Individual Differences, and Applications (pp. 407-427). New York: Springer-Verlag.

[19] Holden, W. R. (1999). learning to learn: 15 vocabulary acquisition activities. Modern English Teacher, 8 (1), $42,47$.

[20] Husltijn, H. J. (1997). Mnemonic methods in foreign language vocabulary learning: Theoretical considerations and pedagogical implications. In J. Coady, \& T. Huckin (Eds.), Second language vocabulary acquisition (p. 203-224). Cambridge: Cambridge University Press.

[21] Levin, J.R. (1993). Mnemonic strategies and classroom learning: A twenty-year report card. The Elementary School Journal, 94(2), 235-244.

[22] Mirhassani, S.A. \& Eghtesadei, A.R. (2007). Improving vocabulary learning through mnemonic devices. ILI Language Teaching Journal, 3(2), 91-98.

[23] Mastropieri, M. A., \& Scruggs, T. E. (1989). Mnemonic social studies instruction: Classroom applications. Remedial and Special Education, 10(3), 40-46.

[24] Oxford. R. (1990). Language Learning Strategies: What Every Teacher Should Know. New York: Newburry House publishers.

[25] Oxford, R. L. \& Scarcella, R.C. (1994). Second language vocabulary learning among adults: State of the art in vocabulary instruction. System, 22, 231-243.

[26] O'Malley, M. \& Chamot, A. (1990). Learning strategies in second language acquisition. Cambridge: Cambridge University Press.

[27] Pressley, M. ,Samuel, J,. Hershey, M.M., Bishop, S.E.L. \& Dickinson, D. (1981). Use of a mnemonic technique to teach young children foreign language vocabulary. Contemporary Educational Psychology, 6(2), 110- 116.Raugh M. R. \& Atkinson, R.C. (1975). A Mnemonic Method for Learning a Second-Language Vocabulary. Journal of Educational Psychology, 67(1), 1-16.

[29] Richards, J.C. \& Renandya, W.A. (eds.) (2002). Methodology in Language Teaching: An Anthology of Current Practice. Cambridge: Cambridge University Press.

[30] Roediger, H.L. (1980).The effectiveness of four mnemonics in ordering recall. Journal of Experimental Psychology: Human Learning and Memory, 6(5), 558-567.

[31] Schmitt, N. (2000). Vocabulary in Language Teaching. Cambridge: Cambridge University Press.

[32] Solso, R. L. (1995). Cognitive Psychology (4th Ed.). Boston: Allyn and Bacon.

[33] Thompson. I. (1987). Memory in language learning. In A. Wenden 8J. Rubin (Eds). Learner Strategies in Language Learning. (pp. 15-30). Newjersy: Prentic-Hall.

[34] Worthen, J. B. \& Hunt, R. R. (2008).Mnemonics: Underlying Processes and Practical Applications. Learning and Memory: A Comprehensive Reference. 2, 145-156.

[35] Wright, A. (1989). Pictures for language learning. Cambridge University Press: Cambridge.

[36] Yates, F. A. (1966). The Art of Memory. London: Routledge \& Kegan Paul.

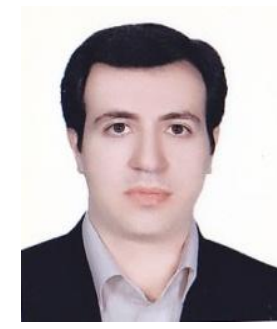

Mohammad Amiryousefi is currently a Ph. D student at the University of Isfahan and the manager of the English department at ACECR, Isfahan University of Technology. He has published some articles on TEFL in national and international journals. His areas of interest include metadiscourse analysis, discourse analysis, CDA, SLA and vocabulary.

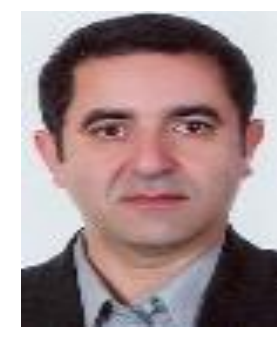

Saeed Ketabi has a Ph. D in Applied Linguistics from the University of Cambridge, England. He teaches various ELT courses at the University of Isfahan, Iran. He has published many books and articles. 